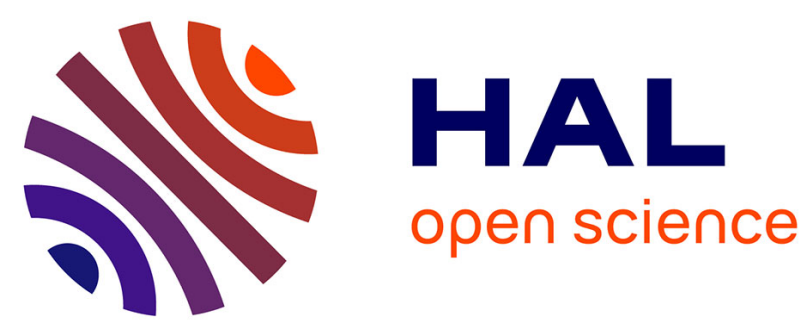

\title{
Sequential Compatibility Effects and Cognitive Control: Does Conflict Really Matter?
}

\author{
Boris Burle, Sonia Allain, Franck Vidal, Thierry Hasbroucq
}

\section{To cite this version:}

Boris Burle, Sonia Allain, Franck Vidal, Thierry Hasbroucq. Sequential Compatibility Effects and Cognitive Control: Does Conflict Really Matter?. Journal of Experimental Psychology: Human Perception and Performance, 2005, 31 (4), pp.831 - 837. 10.1037/0096-1523.31.4.831 . hal-00093366

\section{HAL Id: hal-00093366 https://hal.science/hal-00093366}

Submitted on 6 Dec 2016

HAL is a multi-disciplinary open access archive for the deposit and dissemination of scientific research documents, whether they are published or not. The documents may come from teaching and research institutions in France or abroad, or from public or private research centers.
L'archive ouverte pluridisciplinaire HAL, est destinée au dépôt et à la diffusion de documents scientifiques de niveau recherche, publiés ou non, émanant des établissements d'enseignement et de recherche français ou étrangers, des laboratoires publics ou privés. 


\title{
OBSERVATION
}

\section{Sequential Compatibility Effects and Cognitive Control: Does Conflict Really Matter?}

\author{
Borís Burle, Sonia Allain, Franck Vidal and Thierry Hasbroucq \\ Université de Provence and Institut de Médecine Navale du Service de Santé des Armées
}

\begin{abstract}
Although it is widely accepted that control mechanisms are necessary for human behavior to be adapted, very little is known about how such mechanisms are recruited. A suggestion to fill the gap was put forward by M. M. Botvinick, T. S. Braver, C. S. Carter, D. M. Barch, and J. D. Cohen (2001), who proposed the conflict-loop theory. This theory has been successful in accounting for the reduction of compatibility effects after an incompatible trial: The level of conflict being, on average, higher during an incompatible trial, more control occurs after such a trial. The authors have tested this prediction by sorting the trials on the basis of amount of conflict (quantified by the electromyographic activity) they presented. A reduction of the compatibility effect was observed after incompatible trials, but it was independent of the level of conflict on previous trials, suggesting that the conflict does not trigger changes in executive control. Consequences for the conflict monitoring model are discussed.
\end{abstract}

Keywords: sequential adjustments, Ne/ERN, conflict-loop theory, partial errors

An important feature of human information processing is its ability to adjust itself to the changing environment. It is usually assumed that such a flexibility is made possible by "control" mechanisms that organize and adjust information processing to the context. Needs for cognitive control have been identified in a variety of tasks, and numerous models have proved to be successful in characterizing the nature of control. However, as clearly pointed out by Botvinick, Braver, Carter, Barch, and Cohen (2001), those models are much less explicit in the way such a control is recruited and optimized, and without an explicit account of such a recruitment, "control remains a sort of homonculus that 'just knows' when to intercede" (p. 624).

\section{The Conflict-Loop Theory}

Recently, the conflict-loop theory (Botvinick et al., 2001; Botvinick, Cohen, \& Carter, 2004; Carter et al., 1998) provided a simple and elegant mechanism for such adjustments. This theory is based largely on connectionist models of compatibility paradigms

Boris Burle, Sonia Allain, Franck Vidal, and Thierry Hasbroucq, Centre National de la Recherche Scientifique (CNRS), Université de Provence, Laboratorie de Neurobiologie de la Cognition, Marseille, France, and Institut de Médecine Navale du Service de Santé des Armées, Toulon, France. This work was supported by French Ministry of Research Grant ACT54B and by doctoral Grant Direction Générale de l'Armement - CNRS to Sonia Allain. We thank Wery van den Wildenberg, Richard Ivry, Harmut Leuthold, Guido Band, and Bernhard Hommel for helpful comments on previous versions of this article and Bruno Schmidt and Dominique Reybaud for technical assistance.

This is the authors postprint version of the article originally published in Journal of Experimental Psychology: Human Perception and Performance, DOI: 10.1037/00961523.31.4.831. Current address of Boris Burle: Laboratoire de Neuroscience Cognitive, Aix-Marseille Université, CNRS, Centre St Charles - case C, 3 Place Victor Hugo, 13331 Marseille cedex 3, France. E-mail: boris.burle@univ-amu.fr (see, e.g., Cohen, Servan-Schreiber, \& McClelland, 1992) such as the tasks of Stroop (1935), Eriksen (Eriksen \& Eriksen, 1974), and Simon (Craft \& Simon, 1970). In those tasks, the stimulus is made of two dimensions: a relevant one (e.g., the color of the stimulus in the Simon task) and an irrelevant one (e.g., the position of the stimulus), which, more or less automatically, activates the response strongly associated with this dimension (e.g., a left-side stimulus activates a left response). When the two dimensions correspond (compatible trials), the reaction time (RT) is short and error rate is low, whereas if they do not correspond (incompatible trials), RT is longer and error rate increases. This is termed the compatibility effect.

Two important aspects of connectionist models of compatibility are (a) that the responses are in competition (i.e., as soon as one response is activated, it sends an inhibition proportional to its own activation to the alternative responses) and (b) that an "attentional" module implements the instructions given to the participant (e.g., respond to the stimulus color in the Simon task) by biasing the connections between units involved in the processing of the relevant dimension. The compatibility effects are explained by the fact that, in incompatible trials, the incorrect response is activated and inhibits the correct response, hence delaying its execution. The core idea of the conflict-loop theory is that a conflict monitoring module, supposedly located in the anterior cingulate cortex (ACC), measures online the degree of conflict. The conflict is defined as the sum of the product of the activation of the possible responses weighted by the negative connection strengths between them (Botvinick et al., 2001). If only one response is activated, there is no conflict. On the contrary, as soon as at least two responses are activated, conflict occurs. According to this model, cognitive control is recruited if a conflict is detected. Given the simplicity of the core assumptions, the conflict-loop theory aims at providing a general 
account of control mechanisms in a large variety of tasks (Botvinick et al., 2001) and situations (Yeung, Botvinick, \& Cohen, 2004). In a first series of simulations, Botvinick et al. (2001) evaluated the degree of agreement between conflict measures in the model and ACC activations obtained in various experiments. Notably, they related the amount of conflict and its timing to a specific electroencephalographic component called error negativity ( $\mathrm{Ne}$; Falkenstein, Hohnsbein, Hoormann, \& Blanke, 1991) or error related negativity (ERN; Gehring, Goss, Coles, Meyer, \& Donchin, 1993). When participants commit errors in an RT task, this component appears; it starts around response time (or shortly after incorrect electromyography [EMG] onset; Vidal, Hasbroucq, Grapperon, \& Bonnet, 2000), peaks about $70 \mathrm{~ms}$ after the overt response, and is maximum at fronto-central site (Falkenstein et al., 1991; Vidal et al., 2000). It is thought to originate from either the ACC or the Supplementary Motor Area, or from both (Dehaene, Posner, \& Tucker, 1994). Although this component was first interpreted as reflecting error detection (Coles, Scheffers, \& Holroyd, 2001; Falkenstein et al., 1991; Gehring et al., 1993 ), it has been reinterpreted as reflecting the amount of conflict as defined in the model (Botvinick et al., 2001; van Veen \& Carter, 2002; Yeung et al., 2004). The simulations revealed reasonable agreement between the model's predictions and the observed amplitude (Botvinick et al., 2001) and timing (Yeung et al., 2004) of the Ne. In the second set of simulations, Botvinick et al. (2001) addressed the impact of conflict measurement on control. Notably, they applied the conflict theory to an Eriksen task to account for sequential adjustment effects. In this task, the compatibility effect depends largely on the nature of the previous trial: It is much reduced, or even disappears, when the previous trial was incompatible compared with when the preceding trial was compatible (Gratton, Coles, Sirevaag, Eriksen, \& Donchin, 1988). Such a sequential effect is also present in other compatibility tasks, like Simon's (Stürmer, Leuthold, Soetens, Schroter, \& Sommer, 2002). Although some authors have argued that those sequential effects are due merely to stimulus transition effects (Hommel, 1998; Hommel, Proctor, \& Vu, 2004; Mayr, Awh, \& Laurey, 2003), they are largely considered as reflecting cognitive control (Botvinick et al., 2001; Ridderinkhof, 2002; Stürmer et al., 2002) ${ }^{1}$.

The conflict interpretation of this reduction is as follows: The incorrect response being more often activated in incompatible trials than in compatible ones, the conflict is higher. Following a high-conflict trial, the attentional module increases its control. As a consequence, interference is reduced on the next trial. It is important to note that, strictly speaking, conflict is independent of compatibility: It depends only on the coactivation of the two responses. Now, the two responses can be activated both in compatible and in incompatible trials. However, the incorrect response being more often activated in incompatible trials, the conflict will be, on average, higher in the incompatible situation than in the compatible one. As a consequence, postconflict adjustments will be, on average, higher after an incompatible trial than after a compatible one. But, if the conflict triggers sequential adjustments, equating the preceding trials in terms of conflict should lead to equivalent adjustments whatever the nature (compatible vs. incompatible) of the preceding trials.

\section{Incorrect Electromyographic Activation As an Index of Conflict}

One major problem is to estimate the level of conflict on a trialby-trial basis. Indeed, conflict is a covert process, not visible on behavior, occurring at the level of response activation. Electrophysiological indices have proven to be powerful in revealing response activation (see Coles, 1989, for a review). Among those tools, the Lateralized Readiness Potential has attracted a lot of interest. However, this index is not very useful here, as one can only estimate it after averaging, and it is not possible to estimate response activation on individual trials. Another useful index is the electromyographic (EMG) activity of the muscles involved in the responses (Burle, Possamaï, Vidal, Bonnet, \& Hasbroucq, 2002; Coles, Gratton, Bashore, Eriksen, \& Donchin, 1985; Hasbroucq, Possamaï, Bonnet, \& Vidal, 1999; Smid, Mulder, \& Mulder, 1990). Recording EMG activity has revealed, on a proportion of correct trials, the existence of small EMG activities in muscles associated with the incorrect response (see Figure 1) before the correct response is given ("incorrect-correct" trials) ${ }^{2}$. It is important to note that for our purpose, these subthreshold activities can be detected on a trialby-trial basis. The question is, of course, whether those incorrect EMGs are a good index of the presence of conflict. First, EMG has explicitly been associated with response activation in the conflictloop model (Yeung et al., 2004, Note 2, p. 937). Second, the RT of incorrect-correct trials is longer than the trials without incorrect EMG (Burle et al., 2002; Hasbroucq et al., 1999; Smid et al., 1990), suggesting that the correct response is indeed inhibited by the activation of the incorrect one. Therefore, the incorrect EMG really reflects the activation of the incorrect response, and hence, as two responses are activated, conflict should occur. Within the conflict monitoring framework, a more direct argument for the presence of conflict after an incorrect EMG is the presence of a clear Ne timelocked to the incorrect EMG onset on incorrect-correct trials (Vidal et al., 2000). Such incorrect activations, although more numerous in incompatible situations, are also observed in compatible trials. They offer, therefore, the possibility to decorrelate compatibility and conflict and hence to test whether the reduction of the compatibility effect is due to the level of conflict on the preceding trial to the compatibility per se. We evaluated these two possibilities in a visual version of the Simon task. We sorted the "pure-correct" trials (see the Method section) as a function of both the compatibility and the presence of an incorrect EMG on the previous trial. This led to the 8 categories of trials: 2 compatibility levels on Trial $n$ (compatible vs. incompatible) $\times 2$ compatibility level on Trial $n-1$ (compatible vs. incompatible) $\times 2$ types of trials on $n-1$ (pure-

\footnotetext{
${ }^{1}$ It is important to dissociate the mechanisms triggering control adjustments from the mechanisms by which such sequential effects occur (e.g., gating of the direct route, better suppression of the incorrect response activation, stimulus-response binding). Here we are interested in mechanisms triggering sequential adjustments, not in the one responsible for them, as data in this study do not shed much light on this issue.

${ }^{2}$ Incorrect EMGs can also occur after the correct response. They are, however, less frequent and are not sensitive to compatibility (Smid et al., 1990). Furthermore, no conflict seems to occur for those late EMG activities, as they do not generate any Ne (Allain, Carbonnell, Burle, Hasbroucq, \& Vidal, 2004).
} 


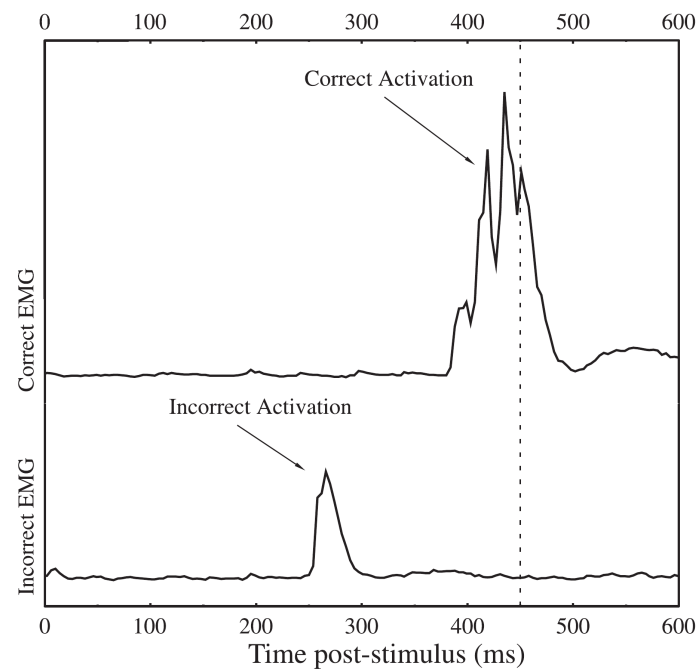

Figure 1. Example of a representative incorrect-correct trial recorded in this task. Rectified electromyographic activity of the muscles involved (correct activation) and noninvolved (incorrect EMG) in the correct response as a function of poststimulus time (in ms). The vertical dashed lines indicate the moment of the mechanical response. This trace comes from an incompatible trial in the speed condition. EMG = electromyography.

correct vs. incorrect-correct). It is important to note that, although the presence of an incorrect EMG evidences the presence of conflict, the opposite is not true. Indeed, conflict can occur at a more central level, without peripheral correlate. This is especially true for incompatible pure-correct trials, in which conflict likely also occurs. However, it seems reasonably safe to consider that on compatible pure-correct trials, the level of conflict, if any, must be low and lower than on compatible incorrect-correct trials. Therefore, if the sequential adjustments depend on conflict on the previous trial, the compatibility effect should be much reduced after compatible incorrect-correct trials than after compatible pure-correct trials. As the conflict is very high whenever an incorrect EMG occurs, sequential effects should be similar after incorrect-correct compatible and incorrect-correct incompatible trials. Note that such an outcome would also invalidate sequential effect explanation in terms of features-integration (Hommel et al., 2004) or stimulus- specific priming (Mayr et al., 2003), as the stimulus transitions are independent of conflict. Furthermore, as executive control is known to depend on the emphasis put on accuracy (Gehring et al., 1993), the speed-accuracy trade-off was manipulated through the task instruction. Such manipulation allows one to check whether the sequential adjustments (compatibility reduction after incompatible trials) are affected by the response strategy of the participants.

\section{Method}

\section{Participants}

Twelve participants ( 2 women, 10 men, ages $23-52$ years, M $=35$ ) volunteered for the experiment. They all had normal (or corrected-to- normal) vision and gave their informed consent.

\section{Apparatus and task}

The participants were seated in a chair, facing a computer screen (distance $2.1 \mathrm{~m}$ ). The stimuli were colored (yellow or blue)-filled circles, $2.5 \mathrm{~cm}$ in diameter, appearing either on the right or the left of a fixation point (Stim system, Neuroscan, El Paso, TX; total visual angle: $0.68^{\circ}$, eccentricity: $1.64^{\circ}$ ). Depending on the color of the stimulus, participants had to flex either the right or the left thumb so as to depress the key of a response pad (Neuroscan). Half the participants had to give a right response when the yellow disk was presented (and a left response for the blue disk), whereas the other half had to perform the opposite mapping. When the stimulus appeared on the side ipsilateral to the required response, the trial was termed compatible; it was termed incompatible in the alternative case. The two colors and the two sides of stimulation were equiprobable. EMG was recorded from the flexor pollicis brevis of each hand, by paired surface $\mathrm{Ag} / \mathrm{AgCl}$ electrodes, amplified $(5,000$ times), filtered (bandwidth: $10 \mathrm{~Hz}-1 \mathrm{kHz}$ ), full wave rectified, integrated (integration window: $5 \mathrm{~ms}$ ), and then digitized (sampling rate: $256 \mathrm{~Hz}$ ). The electroencephalogram (EEG) was recorded from $15 \mathrm{Ag} / \mathrm{AgCl}$ scalp electrodes. The reference and ground were on the right and left mastoids, respectively. Impedances were kept below $5 \mathrm{k} \Omega$. To estimate the time course of the surface Laplacian (Babiloni, Cincotti, Carducci, Rossini, \& Babiloni, 2001) by a modified version (MacKay, 1983) of the source derivation method (Hjorth, 1975), we used an electrode configuration that partly differs from the standard 10-20 electrode placement system. This configuration permitted the Laplacian to be estimated at 7 electrodes, called nodal electrodes (see Tandonnet, Burle, Hasbroucq, \& Vidal, 2005, and Vidal et al., 2000, for more details). The distance between a nodal electrode and its three surrounding electrodes was $1 / 20$ th of the inion-nasion plus tragus-tragus distance (i.e., $3.7 \mathrm{~cm}$, on average). Only the Laplacian obtained over $\mathrm{Cz}$ (where the $\mathrm{Ne}$ was maximal) is presented here. The baseline was chosen between 20 $\mathrm{ms}$ and $50 \mathrm{~ms}$ after EMG onset to facilitate the comparison of the sizes and shapes of the Ne. The vertical electro-oculogram (EOG) was recorded bipolarly between two electrodes, one above and one below the right eye; the horizontal EOG was also recorded bipolarly between two electrodes, at the outer canthus of each eye. EEG and EOG signals were fed into Nicolet amplifiers (Nicolet, Madison, WI), amplified (30,000 times), filtered, and digitized (bandwidth: 0.016-100 Hz, $12 \mathrm{~dB} /$ octave; sampling rate: $256 \mathrm{~Hz}$ ).

\section{Procedure}

The participants first ran 4 training blocks of 64 trials and then 16 blocks of 128 trials each. The first-order sequential effects were equilibrated; that is, each stimulus was followed by each other stimuli the same number of times, and the maximum number of stimulus repetitions (color and loca- tion) was set to three. Following the response signal (RS), participants had to press, as soon as possible, one of the buttons of the response pad. This turned off the stimulus, and $500 \mathrm{~ms}$ later, the next RS was delivered. RTs shorter than 130 ms or longer than $815 \mathrm{~ms}$ were discarded: They were considered as anticipations and omissions, respectively. When participants failed to respond within $815 \mathrm{~ms}$, the RS was turned off, and the next RS was delivered $500 \mathrm{~ms}$ later (i.e., $1,315 \mathrm{~ms}$ after the previously omitted RS). In half of the blocks, the participants received an instruction emphasizing accuracy at the cost of slower RT (accurate condi- 
tion), whereas, in the other half, speed was emphasized at the cost of errors (speed instruction). The order of these speed-accuracy conditions was balanced across participants.

\section{Results}

\section{Classification of Trials}

All proportions were arcsine transformed (Winer, 1970) before being analyzed. Participants made more errors in the incompatible situation $(16.46 \%)$ than in the compatible situation $(9.28 \%), \mathrm{F}(1$, $11)=38.05, \mathrm{p}<.01$, and under the speed condition $(18.7 \%)$ than under the accurate condition $(7.27 \%), \mathrm{F}(1,11)=62.12, \mathrm{p}<.0001$. These two factors interacted significantly, $\mathrm{F}(1,11)=11.57, \mathrm{p}<$ .006 (see Table 1). Correct trials were sorted into two categories depending on whether an EMG activity occurred in the wrong response hand. These categories were labeled pure-correct (single EMG activity) and incorrect-correct (dual-activation trials, with the incorrect activation preceding the correct activation; see Hasbroucq et al., 1999). Incorrect-correct trials were more numerous in incompatible $(9.9 \%)$ than in compatible trials $(6.5 \%), \mathrm{F}(1,11)=21.83$, p $<.001$. There was no effect of instruction $(\mathrm{F}<1)$ or interaction between instruction and compatibility, $\mathrm{F}(1,11)=2.38, \mathrm{p}=.15$. Erroneous trials and correct trials following errors were excluded.

\section{RT Results}

Concerning RT, on pure-correct trials, there was a main effect of compatibility, $\mathrm{F}(1,11)=73.57$, $\mathrm{p}<.0001$; a main effect of instruction, $\mathrm{F}(1,11)=47.33, \mathrm{p}<.001$; and a trend toward an interaction between those effects, $\mathrm{F}(1,11)=3.84, \mathrm{p}<.08$ (see Table 1). As already reported (Burle et al., 2002; Hasbroucq et al., 1999), the RT for incorrect-correct trials was longer $(434 \mathrm{~ms})$ than that for purecorrect trials $(350 \mathrm{~ms}), \mathrm{F}(1,11)=118, \mathrm{p}<.0001$; there was a main effect of compatibility, $\mathrm{F}(1,11)=5.13, \mathrm{p}<.05$, and there was a trend toward an interaction between the nature of the trial and the compatibility, $\mathrm{F}(1,11)=3.49, \mathrm{p}<.09$. This interaction reveals that the compatibility effect disappears for the RT of the incorrectcorrect trials ( $\mathrm{F}<1$; see Burle et al., 2002, for more details). There was a main effect of speed instruction, $\mathrm{F}(1,11)=22.45, \mathrm{p}<.001$. This factor did not interact with any other one (all Fs $<1$ ). Concerning the latencies of the incorrect EMG of the incorrect-correct trials (i.e., the time between the stimulus and the onset of the incorrect EMG activity), there was no compatibility effect (compatible, 223 ms; incompatible, $219 \mathrm{~ms} ; \mathrm{F}<1$ ), but a speed instruction effect occurred (accurate, $230 \mathrm{~ms}$; speed, $212 \mathrm{~ms}$; F[1, 11] = 5.62, $\mathrm{p}<$ $.05)$. These two factors did not interact $(\mathrm{F}<1)$. The within-trial difference in latency between the incorrect and correct EMG activities (called correction time by Burle et al., 2002) was not affected by compatibility (compatible, $141 \mathrm{~ms}$; incompatible, $148 \mathrm{~ms}$; F[1, $11]=1.16, \mathrm{p}=.30)^{3}$.

\section{Ne Triggered by Incorrect EMG}

Figure 2 presents the grand-averaged Laplacian obtained over $\mathrm{Cz}$, time locked to the onset of the incorrect EMG of the incorrectcorrect trials. One can see that, shortly after the onset of the incorrect EMG, a negative wave develops, reaching its maximum around $100 \mathrm{~ms}$ after EMG onset. This negative wave, already described for incorrect-correct trials (Scheffers, Coles, Bernstein, Gehring, \&

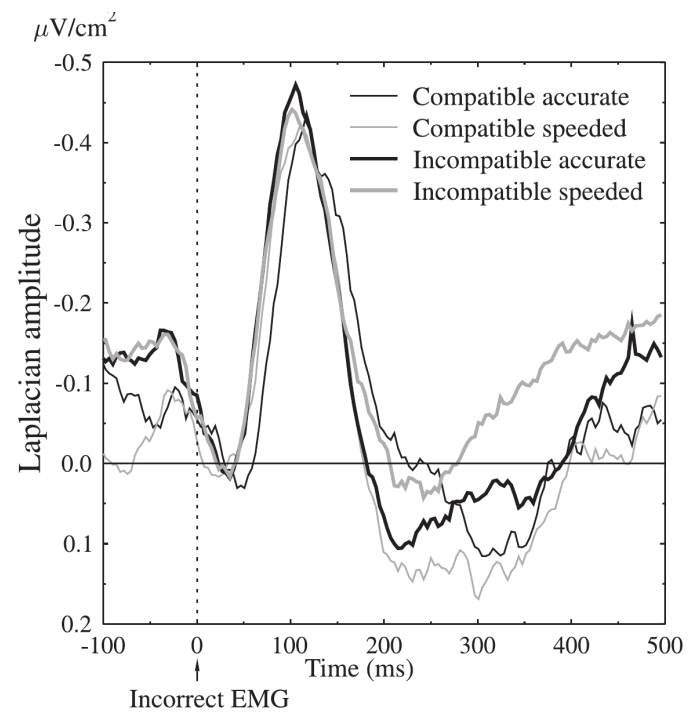

Figure 2. Amplitude of the $\mathrm{Ne}$, observed over $\mathrm{Cz}$, evoked by partial errors (in ordinate: $\mu V / \mathrm{cm}^{2}$ ) as a function of time (in abscissa: $\mathrm{ms}$ ) for each experimental condition; the zero shown on the abcissa corresponds to incorrect electromyography (EMG) onset. The data shown are the Laplacian-transformed traces, and negativity is up.

Table 1

Mean RT in Milliseconds and Percentage of Error as a Function of Compatibility and Speed Instruction

\begin{tabular}{llrllr}
\hline & \multicolumn{2}{c}{ Accurate } & & \multicolumn{2}{c}{ Speed } \\
\cline { 2 - 3 } \cline { 5 - 6 } Trial & $\mathrm{M}$ & \% of Error & & $\mathrm{M}$ & \% of Error \\
\hline Compatible & 357 & 5.46 & & 321 & 13.10 \\
Incompatible & 375 & 9.09 & & 346 & 23.84 \\
\hline
\end{tabular}

Note: $\mathrm{RT}=$ reaction time.

Donchin, 1996; Vidal et al., 2000) and for overt errors (Falkenstein et al., 1991; Gehring et al., 1993), has been interpreted as reflecting conflict (Botvinick et al., 2001; van Veen \& Carter, 2002; Yeung et al., 2004). It is important to note that the Ne can be seen for both incompatible and compatible trials, confirming that incorrect EMG on compatible trials also elicits conflict as defined by Botvinick et al. (2001). However, as a negativity very similar to the Ne has been observed on pure-correct trials (Allain, Carbonnell, Falkenstein, Burle, \& Vidal, 2004; Vidal, Burle, Bonnet, Grapperon, \& Hasbroucq, 2003; Vidal et al., 2000), one may wonder whether the negativity reported in Figure 2 is not the one elicited by the correct EMG. The question as to whether the Ne observed after the incor-

${ }^{3}$ This difference is important as conflict depends on both the strength of the incorrect activation and its overlap with the correct response activation. The numerical difference obtained here, although not significant, is in agreement with previous studies (Burle et al., 2002) and goes in the direction of a larger overlap for compatible trials, suggesting that the conflict should be even larger for compatible trials. Note that such an increase of conflict for congruent trials is the argument advanced by Yeung et al. (2004) to account for the larger $\mathrm{Ne}$ on compatible errors than on incompatible errors. 
rect EMG of incorrect-correct trials is the one seen on pure-correct trials has been addressed by Allain, Carbonnell, Burle, Hasbroucq, and Vidal (2004): They averaged the EEG signal time locked to the incorrect and to the correct EMG on incorrect-correct trials. Allain, Carbonnell, Burle, et al. (2004, Figure 1) clearly observed two independent negativities, one time locked to the incorrect EMG and one smaller, time locked to the correct one. This is also the case in the present study: The Ne peaks around $100 \mathrm{~ms}$ after the incorrect EMG, whereas the mean asynchrony between the incorrect and the correct EMG is $145 \mathrm{~ms}$. Therefore, the peak occurs before the correct EMG onset. The idea that the Ne elicited by the incorrect EMG on incorrect-correct trials is strengthened by the amplitude analysis. We performed an analysis of variance (ANOVA), with trial type as a three-level factor (pure-correct, incorrect-correct, and errors) on the surface under the curve in a time window from -20 to +20 centered on the latency of the peak of the negativity detected on the grand average (see Vidal et al., 2000, for more details). The ANOVA revealed a main effect of trial type, $\mathrm{F}(2,22)=14.32$, $\mathrm{p}<$ .001. Contrast analysis confirmed that $\mathrm{Ne}$ amplitude was smaller on pure-correct $\left(-0.33 \mu \mathrm{V} / \mathrm{cm}^{2}\right)$ trials than on incorrect-correct trials, $1.55 \mu V / \mathrm{cm}^{2}, \mathrm{~F}(1,11)=15.52, \mathrm{p}<.01$. The difference between incorrect-correct and error $\left(-1.85 \mu \mathrm{V} / \mathrm{cm}^{2}\right)$ was, however, not significant, $\mathrm{F}(1,11)=3.74, \mathrm{p}=.08$, Cohen's $d=0.56$.

\section{Sequential Effects}

The analysis involved speed instruction, compatibility on Trial $n$, category of Trial $n-1$, and compatibility of Trial $n-1$ as withinsubject factors. The results are presented in Table 2 for the accurate and speed instruction separately.

Reaction time. The analysis of RT on Trial $n$ revealed a main effect of speed instruction, $\mathrm{F}(1,11)=31.66, \mathrm{p}<.001$; of compatibility on Trial $n, \mathrm{~F}(1,11)=63.64, \mathrm{p}<.001$; and of the category of the previous trial (pure-correct vs. incorrect-correct), $\mathrm{F}(1,11)=$ $12.40, \mathrm{p}<.005$, indicating a lengthening of RT on Trial $n$ when the previous trials contained an incorrect EMG activation. This analysis revealed no effect of compatibility of the previous trial, $\mathrm{F}(1,11)<$ 1. There was an interaction between compatibility on Trial $n$ and on Trial $n-1(\mathrm{~F}(1,11)=38.22, \mathrm{p}<.0001$, replicating the fact that the compatibility effect largely depends on the compatibility on previous trials. The interaction between the compatibility on Trial $n$ and the category of the previous trial was significant, $\mathrm{F}(1$, $11)=6.02, p<.05$. However, this interaction reflects an increased compatibility effect after an incorrect-correct trial, not a decrease (see Figure 3). No other interaction was significant (all ps $>.10$ ), except the second-order interaction between compatibility on Trial $n$, on Trial $n-1$, and the speed instruction, which was marginally significant, $\mathrm{F}(1,11)=3.82, \mathrm{p}=.08$. This interaction may reflect that sequential adjustments are reduced under the speed instruction.

Error rate. The data obtained on error rate essentially replicated the pattern observed on RT. There was a main effect of instruction, $\mathrm{F}(1,11)=32.83, \mathrm{p}<.001$, of compatibility on Trial $n$, $\mathrm{F}(1,11)=24.90, \mathrm{p}<.001$, an effect of the category of the previous trial, $\mathrm{F}(1,11)=10.81, \mathrm{p}<.01$, and no effect of compatibility of Trial $n-1(\mathrm{~F}<1)$. The interaction between compatibility on Trials $n$ and $n-1$ was significant, $\mathrm{F}(1,11)=79.40, \mathrm{p}<.001$. The interaction between compatibility on Trial $n$ and the category of the previous trial was far from significant $(F<1$; see Figure 3$)$. No other interaction was significant (all ps $>.10$ ), except the secondorder interaction between compatibility on Trial $n$, on Trial $n-1$, and the speed instruction, $\mathrm{F}(1,11)=5.80, \mathrm{p}<.05$. Therefore, both $\mathrm{RT}$ and error rate show a reduction of the compatibility effect after an incompatible trial but show no sign of such a reduction after compatible incorrect-correct trials ${ }^{4}$.

\section{Discussion}

In the present study, using a Simon task, we replicated the finding that after an incompatible trial, the compatibility effect is largely reduced or even disappears (Stürmer et al., 2002). The conflict-loop theory explains such a reduction by executive control adjustments following high conflict trials. After a high conflict trial, control is thought to increase to prevent a new conflict. As conflict occurs more often on incompatible trials, adjustments also occur more often after those trials. To test this hypothesis, we dissociated conflict from compatibility by looking at trials on which an incorrect EMG activity occurred, on both compatible and incompatible trials. This dissociation allowed us to show that the reduction of the compatibility effect on Trial $\mathrm{n}$ occurs only after incompatible trials (on Trial $n-1$ ), independent of the presence of any incorrect EMG. Therefore, it seems that sequential adjustments are not triggered by the level of conflict on the previous trial. One can, however, argue that our measure of conflict might not correspond exactly to the conflict defined in the theory. Indeed, as pointed out by Coles (1989), incorrect response activation, and hence conflict, can occur without any peripheral (EMG) signs. More specifically, one may argue that the presence of an incorrect EMG on a compatible trial (incorrect-correct compatible) does not prove the presence of conflict. However, according to the conflict monitoring model, the conflict is reflected in the amplitude of the Ne (Yeung et al., 2004), which was similar for compatible and incompatible in the present study. Therefore, following the model, conflict clearly occurred on compatible incorrect-correct trials. Now, despite the presence of conflict (as indicated by the $\mathrm{Ne}$ ) on those trials, no reduction of the Simon effect was obtained on the next trial. The conflict-loop theory is based on two main assumptions: (a) Conflict is reflected by the ACC activity, whose electrophysiological correlate is the $\mathrm{Ne}$, and (b) conflict triggers sequential adjustments. The present data show that at least one of the two is incorrect. One possibility to accommodate the conflict model with the present data is that sequential effects are not triggered by conflict. Note, however, that in this case, several arguments in favor of the conflict-loop theory (Botvinick et al., 2001; Yeung et al., 2004) need to be reevaluated. More important, if conflict detection is not used to set up adaptive adjustments, the function of such a conflict detection loses most of its interest. Another possibility could be that sequential adjustments

${ }^{4} \mathrm{~A}$ similar pattern of results was also obtained on the percentage of incorrect-correct trials following either a pure-correct or an incorrect- correct trial. However, there were too few incorrectcorrect trials following an incorrect-correct trial for a reliable analysis (too many cells were at zero). If we restrict the analysis when Trial $n-1$ was pure-correct, we replicate the interaction between compatibility on Trials $n$ and $n-1, \mathrm{~F}(1,11)=27.75, \mathrm{p}<.001$, indicating that a compatibility effect was observed when $n-1$ was compatible, $\mathrm{F}(1,11)=43.73, \mathrm{p}<.0001$, but not when $n-1$ was incompatible $(\mathrm{F}<1)$. 
Table 2

Mean RT in Milliseconds and Percentage of Error as a Function of Compatibility and Speed Instruction

\begin{tabular}{|c|c|c|c|c|c|c|c|c|}
\hline \multirow[b]{3}{*}{ Trial $n-1$} & \multicolumn{4}{|c|}{ Accurate } & \multicolumn{4}{|c|}{ Speed } \\
\hline & \multicolumn{2}{|c|}{ Compatible } & \multicolumn{2}{|c|}{ Incompatible } & \multicolumn{2}{|c|}{ Compatible } & \multicolumn{2}{|c|}{ Incompatible } \\
\hline & M & $\%$ of Error & M & $\%$ of Error & M & $\%$ of Error & M & $\%$ of Error \\
\hline Compatib & 339 & 2.95 & 383 & 1340 & 299 & 8.96 & 340 & 33.97 \\
\hline Compatible IC & 342 & 2.40 & 398 & 12.12 & 313 & 5.74 & 354 & 26.79 \\
\hline Incompatible PC & 365 & 8.07 & 357 & 3.85 & 321 & 18.35 & 319 & 15.80 \\
\hline Incompatible IC & 360 & 7.35 & 362 & 5.93 & 333 & 20.62 & 342 & 11.26 \\
\hline
\end{tabular}

Note: $\mathrm{RT}=$ reaction time; $\mathrm{PC}=$ pure-correct trials; $\mathrm{IC}=$ Incorrect-Correct trials; $\mathrm{EMG}=$ electromyography.

are triggered by a "conflict-like" detection but that such a "conflict" is not reflected in the amplitude of the Ne. Here again, an important consequence would be that several strong arguments in favor of the conflict monitoring model based on the fit between the Ne and conflict (Yeung et al., 2004) vanish. From a functional point of view, if the $\mathrm{Ne}$ does not index conflict, it could reflect the activity of a response evaluation process, independent of response competition, whose activity could change as a function of the degree of mismatch between an optimum response and the actual performed response (Allain, Hasbroucq, Burle, Grapperon, \& Vidal, 2004; Holroyd, 2004). Such an interpretation fits nicely with the idea that the $\mathrm{Ne}$ is not restricted to erroneous activities (Allain, Carbonnell, Falkenstein, et al., 2004; Allain, Hasbroucq, et al., 2004; Vidal et al., 2000) but is also observed on correct trials. In conclusion, it appears that, although the conflict model has been very successful in accounting for both the $\mathrm{Ne}$ data and sequential effects separately, it has difficulty in accounting for both at the same time.

\section{References}

Allain, S., Carbonnell, L., Burle, B., Hasbroucq, T., \& Vidal, F. (2004). Electromyographic activities and the Ne. In M. Ullsperger \& M. Falkenstein (Eds.), Errors, conflicts, and the brain: Current opinions on performance monitoring (pp. 2127). Leipzig, Germany: Max Planck Institute of Cognitive Neuroscience.

Allain, S., Carbonnell, L., Falkenstein, M., Burle, B., \& Vidal, F. (2004). The modulation of the Ne-like wave on correct responses foreshadows errors. Neuroscience Letters, 372, 161166.

Allain, S., Hasbroucq, T., Burle, B., Grapperon, J., \& Vidal, F. (2004). Response monitoring without sensory feedback. Clinical Neurophysiology, 115, $2014-2020$.

Babiloni, F., Cincotti, F., Carducci, F., Rossini, P. M., \& Babiloni, C. (2001). Spatial enhancement of EEG data by surface Laplacian estimation: The use of magnetic resonance imaging-based head models. Clinical Neurophysiology, 112, 724-727.

Botvinick, M. M., Braver, T. S., Carter, C. S., Barch, D. M., \& Cohen, J. D. (2001). Conflict monitoring and cognitive control. Psychological Review, 108, 624-642.

Botvinick, M. M., Cohen, J. D., \& Carter, C. S. (2004). Conflict monitoring and anterior cingulate cortex: An update. Trends in Cognitive Sciences, 8, 539-546.
Burle, B., Possamaï, C. A., Vidal, F., Bonnet, M., \& Hasbroucq, T. (2002). Executive control in the Simon effect: An electromyographic and distributional analysis. Psychological Research, 66, $324-336$.

Carter, C. S., Braver, T. S., Barch, D. M., Botvinick, M. M., Noll, D., \& Cohen, J. D. (1998, May 1). Anterior cingulate cortex, error detection, and the on-line monitoring of performance. Science, 280, 747-749.

Cohen, J. D., Servan-Schreiber, D., \& McClelland, J. L. (1992). A parallel distributed processing approach to automaticity. American Journal of Psychology, 105, 239 -269.

Coles, M. G. H. (1989). Modern mind- brain reading: Psychophysiology, physiology, and cognition. Psychophysiology, 26, 251269.

Coles, M. G. H., Gratton, G., Bashore, T. R., Eriksen, C. W., \& Donchin, E. (1985). A psychophysiological investigation of the continuous flow of human information processing. Journal of Experimental Psychology: Human Perception and Performance, 11, $529-552$.

Coles, M. G. H., Scheffers, M. K., \& Holroyd, C. B. (2001). Why is there an ERN/Ne on correct trials? Response representations, stimulus-related components, and the theory of errorprocessing. Biological Psychology, 56, 173-189.

Craft, J. L., \& Simon, J. R. (1970). Processing symbolic information from a visual display: Interference from irrelevant directional cue. Journal of Experimental Psychology, 83, 415- 420.

Dehaene, S., Posner, M., \& Tucker, D. (1994). Localization of a neural system for error detection and compensation. Psychological Science, 5, 303-305.

Eriksen, B. A., \& Eriksen, C. W. (1974). Effects of noise letters upon the identification of target letter in a non-search task. Perception $\mathcal{E}$ Psychophysics, 16, 143-149.

Falkenstein, M., Hohnsbein, J., Hoormann, J., \& Blanke, L. (1991). Effects of cross-modal divided attention on late ERP components: II. Error processing in choice reaction tasks. Electroencephalography and Clinical Neurophysiology, 78, 447- 455.

Gehring, W. J., Goss, B., Coles, M. G. H., Meyer, D. E., \& Donchin, E. (1993). A neural system for error detection and compensation. Psychological Science, 4, 385-390.

Gratton, G., Coles, M. G. H., Sirevaag, E. J., Eriksen, C. W., \& Donchin, E. (1988). Pre- and poststimulus activation of response channels: A psychophysiological analysis. Journal 
of Experimental Psychology: Human Perception and Performance, 14, 331-344.

Hasbroucq, T., Possamaï, C.-A., Bonnet, M., \& Vidal, F. (1999). Effect of the irrelevant location of the response signal on choice reaction time: An electromyographic study in humans. Psychophysiology, 36, 522-526.

Hjorth, B. (1975). An on-line transformation of EEG scalp potentials into orthogonal source derivations. Electroencephalography and Clinical Neurophysiology, 39, 526-530.

Holroyd, C. (2004). A note on the N200 and the feedback ERN. In M. Ullsperger \& M. Falkenstein (Eds.), Errors, conflicts, and the brain. Current opinions on performance monitoring (pp. 211-218). Leipzig, Germany: Max Planck Institute of Cognitive Neuroscience.

Hommel, B. (1998). Event files: Evidence for automatic integration of stimulus-response episodes. Visual Cognition, $5(1 \&$ 2), 183-216.

Hommel, B., Proctor, R. W., \& Vu, K.-P. L. (2004). A featureintegration account of sequential effects in the Simon task. Psychological Research, 68, 1-17.

MacKay, D. M. (1983). On-line source density computation with a minimum of electrodes. Electroencephalography and Clinical Neurophysiology, 56, $696-698$.

Mayr, U., Awh, E., \& Laurey, P. (2003). Conflict adaptation effects in the absence of executive control. Nature Neuroscience, 6, $450-452$.

Ridderinkhof, K. R. (2002). Activation and suppression in conflict tasks: Empirical clarification through distributional analyses. In W. Prinz \& B. Hommel (Eds.), Common mechanisms in perception and action: Attention and performance XIX (pp. 494 -519). Oxford, England: Oxford University Press.

Scheffers, M. K., Coles, M. G. H., Bernstein, P., Gehring, W. J., \& Donchin, E. (1996). Event-related brain potentials and error- related processing: An analysis of incorrect responses to go and no-go stimuli. Psychophysiology, 33, 42-53.

Smid, H. G. O. M., Mulder, G., \& Mulder, L. J. M. (1990). Selective response activation can begin before stimulus recognition is complete: A psychophysiological and error analysis of the continuous flow. Acta Psychologica, 74, 169 -201.

Stroop, J. R. (1935). Studies of interference in serial verbal reactions. Journal of Experimental Psychology, 18, 643- 662.

Stürmer, B., Leuthold, H., Soetens, E., Schroter, H., \& Sommer, W. (2002). Control over location-based response activation in the Simon task: Behavioral and electrophysiological evidence. Journal of Experimental Psychology: Human Perception and Performance, 28, 1345-1363.

Tandonnet, C., Burle, B., Hasbroucq, T., \& Vidal, F. (2005). Spatial enhancement of EEG traces by surface Laplacian estimation: Comparison between local and global methods. Clinical Neurophysiology, 116, $18-24$.

van Veen, V., \& Carter, C. (2002). The timing of action-monitoring processes in the anterior cingulate cortex. Journal of Cognitive Neuroscience, 14, 593-602.

Vidal, F., Burle, B., Bonnet, M., Grapperon, J., \& Hasbroucq, T. (2003). Error negativity on correct trials: A reexamination of available data. Biological Psychology, 64, 265-282.

Vidal, F., Hasbroucq, T., Grapperon, J., \& Bonnet, M. (2000). Is the "error negativity" specific to errors? Biological Psychology, $51,109-128$.

Winer, B. J. (1970). Statistical principles in experimental design. London: McGraw-Hill.

Yeung, N., Botvinick, M. M., \& Cohen, J. D. (2004). The neural basis of error detection: Conflict monitoring and the error-related negativity. Psychological Review, 111, 931-959. 